University of South Florida

DIGITAL COMMONS

Digital Commons @ University of

@ UNIVERSITY OF SOUTH FLORIDA

South Florida

6-1-2007

\title{
Ocean Currents and Sea Surface Heights Estimated Across the West Florida Shelf
}

Yonggang Liu

University of South Florida

Robert $\mathrm{H}$. Weisberg

University of South Florida, weisberg@marine.usf.edu

Follow this and additional works at: https://digitalcommons.usf.edu/msc_facpub

Part of the Marine Biology Commons

\section{Scholar Commons Citation}

Liu, Yonggang and Weisberg, Robert $\mathrm{H}_{\text {., }}$ "Ocean Currents and Sea Surface Heights Estimated Across the West Florida Shelf" (2007). Marine Science Faculty Publications. 153.

https://digitalcommons.usf.edu/msc_facpub/153

This Article is brought to you for free and open access by the College of Marine Science at Digital Commons @ University of South Florida. It has been accepted for inclusion in Marine Science Faculty Publications by an authorized administrator of Digital Commons @ University of South Florida. For more information, please contact digitalcommons@usf.edu. 


\title{
Ocean Currents and Sea Surface Heights Estimated across the West Florida Shelf
}

\author{
YongGang LiU* AND Robert H. WeIsBerg \\ College of Marine Science, University of South Florida, St. Petersburg, Florida
}

(Manuscript received 7 February 2006, in final form 10 October 2006)

\begin{abstract}
The across-shelf structures of the ocean circulation and the associated sea surface height (SSH) variability are examined on the west Florida shelf (WFS) for the 3-yr interval from September 1998 to December 2001. Five sets of characteristic circulation patterns are extracted from 2-day, low-pass-filtered data using the self-organizing map: extreme upwelling and downwelling structures with strong currents, asymmetric upwelling and downwelling structures with moderate currents, and a set of transitional structures with weak currents. The temporal variations of these structures are coherent with the local winds on synoptic weather time scales. On seasonal time scales they are related to both the local winds and the water density variations. The circulation is predominantly upwelling during autumn to spring months (October-April) and downwelling during summer months (June-September). Coastal sea level fluctuations are related to both the dynamical responses of the inner shelf circulation to meteorological forcing and the offshore SSH. On long time scales, the offshore SSH variations appear to dominate, whereas on synoptic weather time scales, the inner shelf wind-driven circulation responses are largest. The across-shelf distribution of SSH is estimated from the velocity, hydrography, wind, and coastal sea level data, and the results are compared with satellite altimetry data, thereby providing a means for calibrating satellite altimetry on the shelf.
\end{abstract}

\section{Introduction}

Wind-driven upwelling and downwelling circulations play important roles in determining coastal ocean water properties (Huyer 1990; Smith 1995). Observational studies of coastal upwelling and downwelling began with across-shelf hydrographic sections, and these were later augmented with velocity data from across-shelf arrays of current meters (e.g., Mooers et al. 1976; Kundu and Allen 1976; Brink et al. 1980, 1983; Lentz et al. 2003). Determining the across-shelf flow structures within upwelling regions was difficult with current meters since these sampled neither the near surface nor the near bottom regions (Huyer 1990). The introduction of acoustic Doppler current profilers (ADCP) improved on these sampling capabilities, but across-shelf arrays of ADCPs maintained over several years are rare.

\footnotetext{
* Current affiliation: School of Oceanography, University of Washington, Seattle, Washington.
}

Corresponding author address: Yonggang Liu, School of Oceanography, University of Washington, Seattle, WA 98115.

E-mail: yliu18@gmail.com
Schematics of coastal upwelling and downwelling structures (e.g., Huyer 1990), suggest asymmetries in the velocity and density fields. Observations of asymmetric behavior are few, however, in part because coastal upwelling receives more attention than coastal downwelling by virtue of its ecological importance (Huyer 1983; Brink 1983; Brink et al. 1983).

Here we consider the across-shelf structure of the circulation on the west Florida shelf (WFS) and the relationship between the currents and the sea surface height (SSH). The WFS is a wide, gently sloping continental shelf located in the eastern Gulf of Mexico. Weisberg et al. (2005) reviews the circulation observed and modeled over various time scales. Early inferences on the WFS seasonal circulation were from drift bottles (e.g., Tolbert and Salsman 1964). Measurements with in situ moorings began in the 1970s (e.g., Niiler 1976; Price et al. 1978; Weatherly and Martin 1978; Blaha and Sturges 1981; Mitchum and Sturges 1982; Marmorino 1983a,b; Halper and Schroeder 1990; Weatherly and Thistle 1997), but these were mostly of short duration and with limited spatial coverage. Longer-duration measurements with ADCPs, first at a single point (47-m isobath) and then at multiple locations across the shelf, began with Weisberg et al. (1996), followed by Siegel

DOI: $10.1175 / \mathrm{JPO} 3083.1$

(C) 2007 American Meteorological Society 
(1999) and Meyers et al. (2001). Following these exploratory datasets, focus was concentrated on the inner shelf for which Liu and Weisberg (2005b) analyzed the spatial patterns of current variability from October 1998 to September 2001. The asymmetric upwelling and downwelling responses at synoptic scale identified by Weisberg et al. (2001) were further described as follows: 1) southeastward currents are generally stronger than northwestward currents, 2) the coastal jet axis is located farther offshore for southeastward currents than for northwestward currents, and 3) the velocity vector rotations with depth are larger in shallower water when the currents are southeastward relative to when the currents are northwestward. A coherent seasonal variation was also found such that during winter the inner shelf currents tend to be upwelling favorable (southeastward), whereas during summer they are downwelling favorable (northwestward). Some of these across-shelf structures and seasonality were also found in WFS numerical model simulations (e.g., Li and Weisberg 1999a,b; Yang and Weisberg 1999; Weisberg et al. 2000, 2001; He and Weisberg 2002, 2003). Recently, however, Ohlmann and Niiler (2005) in their interpretation of surface drifter tracks from northern Gulf of Mexico suggested that a circulation seasonality is not pronounced on the WFS.

Satellite altimetry provides valuable information on the deep ocean circulation (e.g., Douglas et al. 1987; Fu et al. 1994; Fu and Cheney 1995; Lagerloef et al. 1999). Direct comparisons with in situ measurements of SSH are mostly from the open ocean using sea level records from oil platforms (e.g., Christensen et al. 1994; Ménard et al. 1994; Born et al. 1994; Haines et al. 2003), island tide gauges (e.g., Mitchum 1994, 1998, 2000; Cheney et al. 1994; Verstraete and Park 1995), and GPS buoys (e.g., Bonnefond et al. 2003; Watson et al. 2003), and dynamic height estimates from hydrography (e.g., Cheney et al. 1994; Picaut et al. 1995; Katz et al. 1995; Menkes et al. 1995) and inverted echo sounders (e.g., Picaut et al. 1995; Katz et al. 1995; Teague et al. 1995). In contrast, comparisons with SSH observations near the coast are rare because coastal ocean altimetric observations are not as readily interpretable because of a number of factors (Vignudelli et al. 2005). Complimenting conventional altimetric sensors is a new GPS coastal altimetry technique introduced by Treuhaft et al. (2001). Regardless of technique the calibration of coastal altimetry requires independent SSH estimations within shallow water environments.

Early observational studies of the WFS sea level responses to wind forcing focused on coastal sea level (Marmorino 1982; Cragg et al. 1983). An across-shelf sea level distribution was examined by Marmorino (1983b) using a tide gauge at Cedar Key, Florida, and bottom pressure records from two offshore moorings. Bottom pressure fluctuations were found to decay offshore, and the across-shelf pressure gradient was used to estimate the along-shelf geostrophic velocity for comparison with observed currents. In a related set of papers, Mitchum and Clarke (1986a,b) applied a frictional, wind-forced, barotropic long-wave model to the WFS. The first of these developed an equation for the pressure (sea level) response to along-shelf synoptic wind forcing over a region extending from the coast to where the water depth is three times the Ekman depth in order to provide a boundary condition for the longwave model. Through comparisons with coastal sea level they suggested that the pressure field (sea level) is controlled by first mode long waves, consisting of the sum of forced waves evolving with the wind stress and a free wave generated at the Florida Keys, and a frictional inner shelf correction proportional to the alongshelf wind stress.

The present paper links the coastal ocean circulation with the SSH and shows how coastal sea level relates to both inner shelf and deeper ocean variations. An SSH equation is derived that takes into account the inner shelf contributions by the barotropic and baroclinic along-shelf currents and the across-shelf wind stress. Section 2 describes the datasets. Section 3 provides the analysis methods and the SSH equation derivation. With the SSH equation related to the velocity, hydrography, local wind stress, and coastal sea level, there is a basis for estimating the absolute SSH from these data. Section 4 describes the across-shelf structures of the inner shelf currents, and section 5 diagnoses the hydrographic data to give the portion of the across-shelf current structure due to baroclinicity. The results are combined in section 6 to provide an SSH analysis and a comparison with satellite altimetry. The findings are then discussed and summarized in section 7 .

\section{Data}

Five ADCP moorings were maintained between the 10- and 50-m isobaths offshore of Sarasota, Florida (Fig. 1) from October 1998 to September 2001. Moorings EC5 and EC4, located at the 10- and 20-m isobaths, respectively, sampled with bottom-mounted, upwardlooking ADCPs that measured velocity at $0.5-\mathrm{m}$ intervals from $2 \mathrm{~m}$ off the bottom to $2-3 \mathrm{~m}$ from the surface. Moorings NA2, EC3, and EC2, located at the 25-, 30-, and $50-\mathrm{m}$ isobaths, respectively, sampled with surface buoy-mounted, downward-looking ADCPs that measured velocity at either 0.5 - or 1-m intervals from 2-3 m below the surface to $2-3 \mathrm{~m}$ off the bottom. The ADCPs were either $600-\mathrm{kHz}$ narrow-band or $300-\mathrm{kHz}$ broad- 


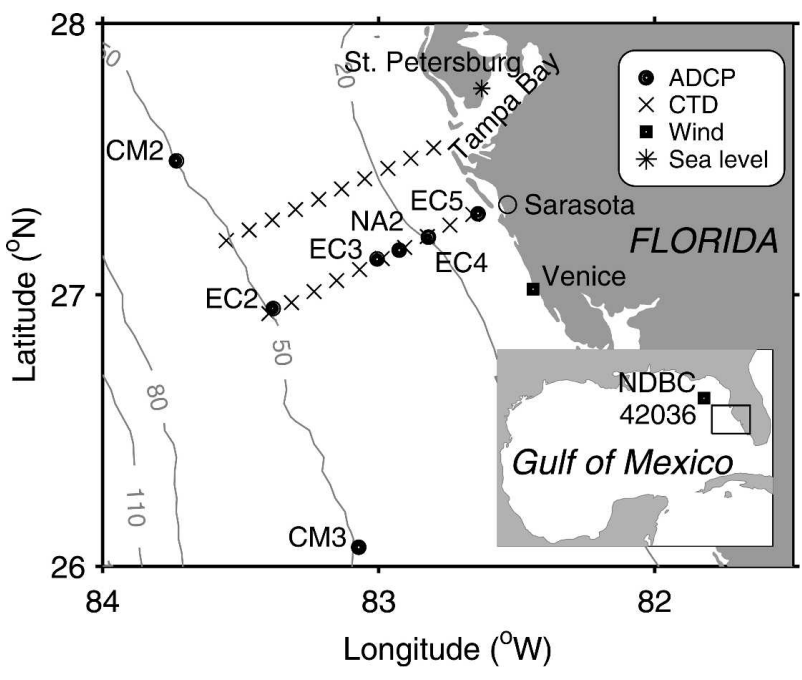

FIG. 1. West Florida shelf topography (isobaths; $m$ ) and the locations of the ADCP, CTD, wind, and coastal sea level stations.

band units. The velocity data at all of these moorings were collected hourly as averages of 3601 -s samples during the first 6 min of each hour.

Monthly hydrographic data were collected along three WFS transects from June 1998 to December 2001. Here we use data inshore of the 50-m isobath from two transects taken offshore of Tampa Bay and Sarasota, each with 10 CTD stations (Fig. 1). Figure 2 shows the hydrographic sampling relative to the ADCP moorings. Ancillary data include hourly winds and atmospheric pressure at National Data Buoy Center (NDBC) Buoy 42036 and Venice, Florida, downloaded from the National Oceanic and Atmospheric Administration (NOAA)/NDBC Web site (http://www.ndbc.noaa.gov/), hourly sea level at St. Petersburg, downloaded from the NOAA/National Ocean Service (NOS) Web site (http://www.co-ops.nos.noaa.gov/), and sea level anomaly data merged from multialtimetry sensors [TOPEX/Poseidon or Jason-1 + European Remote Sensing Satellite (ERS)-1/2 or Envisat], downloaded from the Archiving, Validation, and Interpretation of Satellite Oceanographic data (AVISO) Web site (http://las.aviso.oceanobs.com/las/servlets/dataset). The sea level anomalies are defined as differences between the observed SSH and the 7-yr mean sea level.

\section{Methods}

a. Methods used for extracting across-shelf structures

\section{1) EMPIRICAL ORTHOGONAL FUNCTIONS}

Time-domain empirical orthogonal functions (EOF), as a method for extracting patterns from time series of spatial maps, have wide application in oceanography (e.g., Davis 1976; Klinck 1985; Lagerloef and Bernstein 1988; Samelson et al. 2002). Based on correlation, EOF separates data into $N$ orthogonal modes, each with a variance, a dimensional spatial pattern $F_{n}(x)$, and a nondimensional principal component $(\mathrm{PC})$ time series $\alpha_{n}(t)$. Thus, the EOF representation of velocity anomalies is

$$
V(x, t)=\sum_{n=1}^{N} \alpha_{n}(t) F_{n}(x)
$$

\section{2) Self-Organizing MaP}

The self-organizing map (SOM) is relatively new to oceanography. As an artificial neural network based on unsupervised learning, the SOM is a nonlinear, ordered mapping of high-dimensional input data onto a regular, low-dimensional (usually two-dimensional) array (Kohonen 1982, 2001). As a pattern recognition and classification tool, the SOM has been applied widely to other disciplines (Kaski et al. 1998; Oja et al. 2003), including meteorology (e.g., Hewitson and Crane 1994, 2002; Malmgren and Winter 1999; Cavazos 2000; Ambroise et al. 2000; Niang et al. 2003; Hong et al. 2005, 2006; Reusch et al. 2007). Recent oceanographic applications are: Ainsworth and Jones (1999), Silulwane et al. (2001), Richardson et al. (2002, 2003), HardmanMountford et al. (2003), Risien et al. (2004), Liu and Weisberg (2005b), Cheng and Wilson (2006), Leloup et al. (2007), and Liu et al. (2006a,b, 2007a,b). Explanations on the SOM workings are found in Richardson et al. (2003) and Liu and Weisberg (2005b), and a performance evaluation of the SOM for feature extraction is reported by Liu et al. (2006b).

\section{b. Sea surface height equations}

Assuming a hydrostatic balance and integrating down from the surface for a right-handed coordinate system with $z$ positive upward and with atmospheric pressure set equal to zero, the pressure $p$ at any level $z$ is

$$
p=\int_{z}^{\eta} \rho g d z^{\prime}
$$

where $\eta$ is the free surface elevation above a zero mean sea surface elevation and $g$ is the gravitational acceleration. Let the density $\rho$ consist of a reference value $\left(\rho_{0}\right)$ and a perturbation $(\varepsilon)$,

$$
\rho=\rho_{0}[1+\varepsilon(x, z)]
$$




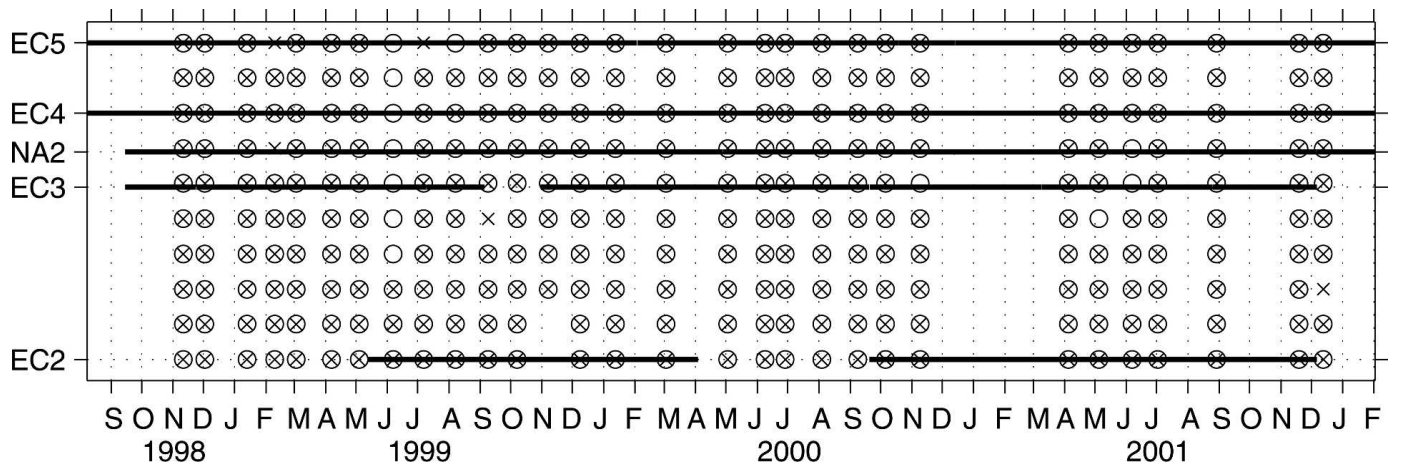

FIG. 2. A timeline diagram showing the acquired concurrent observations of the ADCP (solid lines) and CTD data at the Sarasota (times signs) and Tampa Bay (circles) transects.

where $x$ is in the across-shelf coordinate directed, positive onshore. From Eqs. (2) and (3), the horizontal pressure gradient in the across-shelf direction is

$$
\frac{1}{\rho_{0}} \frac{\partial p}{\partial x}=g \frac{\partial \eta}{\partial x}+g \int_{z}^{\eta} \frac{\partial \varepsilon\left(x, z^{\prime}\right)}{\partial x} d z^{\prime} .
$$

Integrating over the water column, using an integration by parts for the second term on the right-hand side, yields

$\frac{1}{\rho_{0}} \int_{-H}^{0} \frac{\partial p}{\partial x} d z=g H \frac{\partial \eta}{\partial x}+g H \int_{-H}^{0}\left(1+\frac{z}{H}\right) \frac{\partial \varepsilon(x, z)}{\partial x} d z$,

where $H$ is the bottom depth, and assuming $\eta \ll H$ (e.g., Csanady 1979).

Over synoptic and longer time scales, the dominant terms in the depth-averaged, across-shelf momentum balance on the WFS are the Coriolis, the pressure gradient and the wind stress terms (Liu and Weisberg 2005a)

$$
-f \bar{v}=-\frac{1}{\rho_{0} H} \int_{-H}^{0} \frac{\partial p}{\partial x} d z+\frac{\tau_{x}}{\rho_{0} H} .
$$

The along-shelf component of wind stress enters this across-shelf component equation implicitly through the pressure gradient set up by Ekman layer divergence, whereas the across-shelf component of wind stress, $\tau_{x}$, is explicit. Substituting the pressure gradient term from Eq. (5), Eq. (6) becomes

$$
-f \bar{v}=-g \frac{\partial \eta}{\partial x}-g \int_{-H}^{0}\left(1+\frac{z}{H}\right) \frac{\partial \varepsilon(x, z)}{\partial x} d z+\frac{\tau_{x}}{\rho_{0} H} .
$$

Rearranging Eq. (7) and integrating in the across-shelf direction to solve for $\eta$, the across-shelf SSH distribution, $\eta(x)$, may be expressed as

$$
\begin{aligned}
\eta & =\eta_{0}+\eta_{b}+\eta_{c}+\eta_{w}, \\
\eta_{b} & =\int_{0}^{x} \frac{f \bar{v}}{g} d x, \\
\eta_{c} & =-\int_{0}^{x} \int_{-H}^{0}\left(1+\frac{z}{H}\right) \frac{\partial \varepsilon(x, z)}{\partial x} d z d x, \text { and } \\
\eta_{w} & =\int_{0}^{x} \frac{\tau_{x}}{\rho_{0} g H} d x,
\end{aligned}
$$

where $\eta_{0}$ is the reference sea level at the initial integration point (the 50-m isobath in this paper), $\eta_{b}, \eta_{c}$, and $\eta_{w}$ are SSH contributions from the along-shelf depth averaged (barotropic) and baroclinic currents, and the across-shelf wind stress, respectively, which may each be estimated from the observed along-shelf currents, the hydrography, and the across-shelf wind stress, respectively.

Equation (8b) may be written as

$$
\eta_{c}=-\frac{f}{g H} \int_{0}^{x} \int_{-H}^{0} v_{g}(x, z) d z d x,
$$

where $v_{g}$ is the relative along-shelf baroclinic geostrophic velocity,

$$
v_{g}=\frac{g}{f} \int_{z}^{0} \frac{\partial \varepsilon\left(x, z^{\prime}\right)}{\partial x} d z^{\prime} .
$$

By definition of the thermal wind relation, $v_{g}$ is essentially the vertical shear between the currents at two levels. Thus, $v_{g}$ may be calculated directly from the current vertical profiles. Equation (9) then provides an 
alternate method to estimate $\eta_{c}$ from the along-shelf currents' vertical shear.

\section{Across-shelf structure of velocity from the moored ADCPs}

\section{a. EOF results}

To focus on the subtidal variability the velocity data are first low-pass filtered using a cutoff of two days. Five vertical levels extending from the near surface to the near bottom are extracted from each profile so that each of the mooring sites is afforded equal weight in the analysis. Since a time-domain EOF analysis requires continuous input data the longer data gaps at mooring EC2 are filled by linear regression using data at moorings $\mathrm{CM} 2$ and $\mathrm{CM} 3$, all located along the same $(50 \mathrm{~m})$ isobath. Smaller data gaps in other records are filled through linear regression from adjacent stations. The velocity time series are arranged in a two-dimensional array such that each velocity snapshot is in a single row vector and the time series of each velocity component is in a single column. All $u$ components are placed in the first half of the rows followed by all $v$ components. Thus, the input matrix consists of 50 columns ( 5 stations $\times 5$ levels $\times 2$ components) $\times 28201$ rows (hours), and the temporal mean values are removed prior to the EOF analysis. While the east and north velocity components are used in the EOF analysis (so that the matrix will not be ill conditioned) the velocity eigenvector is then rotated to the across- and along-shelf directions for visualization.

The first EOF mode accounts for $71.3 \%$ of the total subtidal velocity variance. The eigenvector shows a coherent pattern shoreward of the 50-m isobath (Fig. 3). The along-shelf currents have the same sign across the inner WFS with a current core located subsurface in the vicinity of the $25-30-\mathrm{m}$ isobaths. The across-shelf currents have opposite signs near the surface and the bottom, consistent with the along-shelf current directions and the traditional Ekman-geostrophic structure of coastal upwelling/downwelling. The along-shelf currents are an order of magnitude larger than the acrossshelf currents. The associated PC shows the temporal variations that occur on synoptic and seasonal time scales. In winter (summer) this first-mode PC tends to be negative (positive) indicating that the inner shelf currents tend to be upwelling (downwelling). These PC variations are visually coherent with the local winds, suggesting that the local winds are the main driver of the inner shelf currents. Correlating this first-mode PC with the major axis component of the wind time series (similarly 2-day low-pass filtered) yields a lagged $(6 \mathrm{~h})$ correlation coefficient of 0.77 . These results are consis-
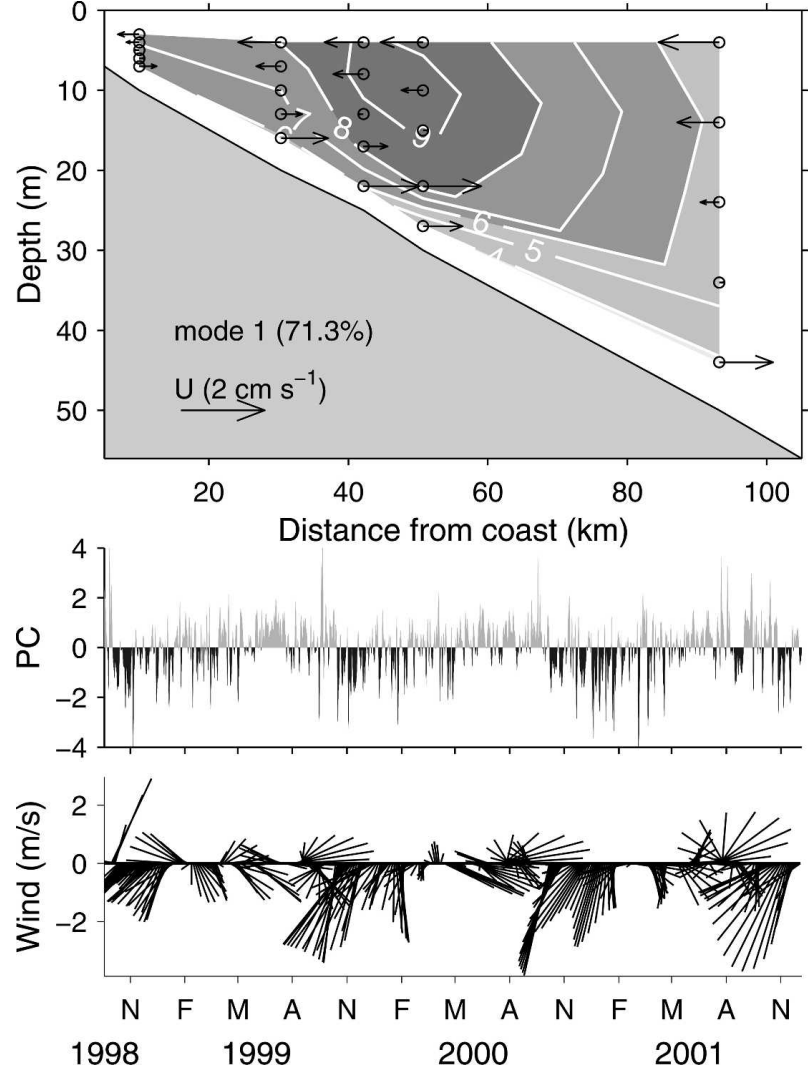

FIG. 3. (top) First-mode eigenvector and (middle) its principal component from a time-domain EOF analysis of 2-day low-passfiltered currents relative to (bottom) 30-day low-pass-filtered, 3-day subsampled winds at Venice. The across- and along-shelf components are shown as vectors and filled contours, respectively. Positive contour values denote northwestward along-shelf currents. Letters F, M, A, and N refer to February, March, April, and November, respectively.

tent with the constant-density model results of $\mathrm{Li}$ and Weisberg (1999a,b) and their associated definition of the inner shelf.

\section{b. SOM results}

The same data are used for the SOM analysis except that the data gaps and the temporal mean values are retained. The SOM parameters are chosen as in Liu et al. $(2006 \mathrm{~b}, 2007 \mathrm{a})$ to be a $3 \times 4$ map size, rectangular lattice, sheet shape, linear initialization, Epanechikov (ep) neighborhood function with a radius of 1 , and batch training algorithm.

\section{1) Synoptic-scale VARiability}

The current structures extracted by the SOM are shown in the top 12 panels of Fig. 4. For each frame of the velocity time series, a best-matching unit (BMU) is identified among the 12 SOM units according to the 

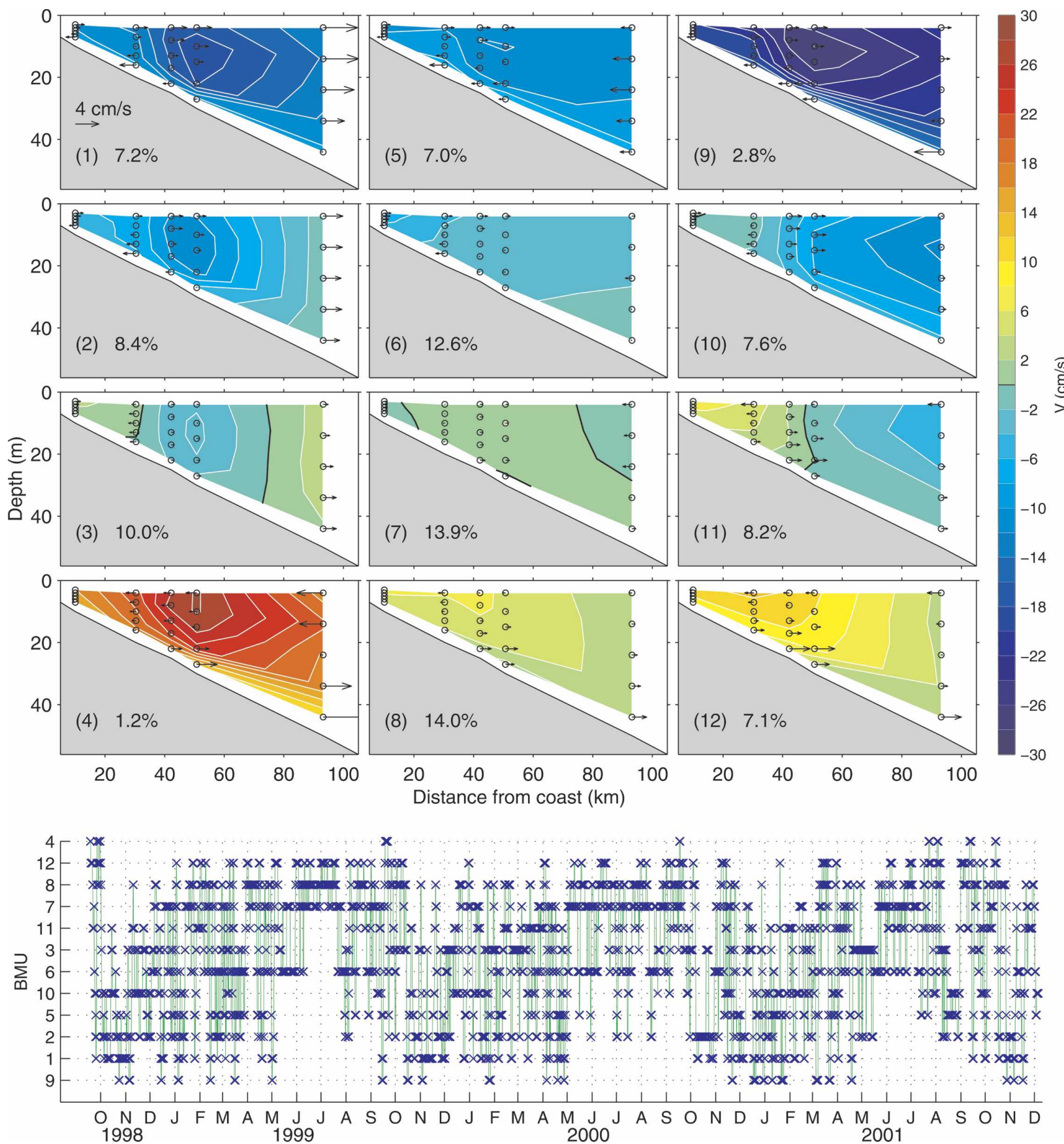

FIG. 4. SOM representation of the 2-day low-pass-filtered velocity data: (top) the $4 \times 3$ SOM and (bottom) the BMU time series. The across- and along-shelf components are vectors and filled contours, respectively. The relative frequency of occurrence (\%) of each pattern is shown in the lower-left corner of each SOM unit.

minimum Euclidian distance (Kohonen 2001). Thus, the BMU time series show the temporal variation of these structures (Fig. 4, bottom panel). To quantify the representation of each unit, a frequency of occurrence is computed by summing the number of times that a given unit is a BMU and dividing by the total record length. Similar structures on the SOM are organized to be neighboring units and dissimilar structures are located farther away from each other. Thus coherent upwelling, downwelling, and transitional structures are found in the upper two rows, the bottom row, and the third row of the SOM, respectively. 

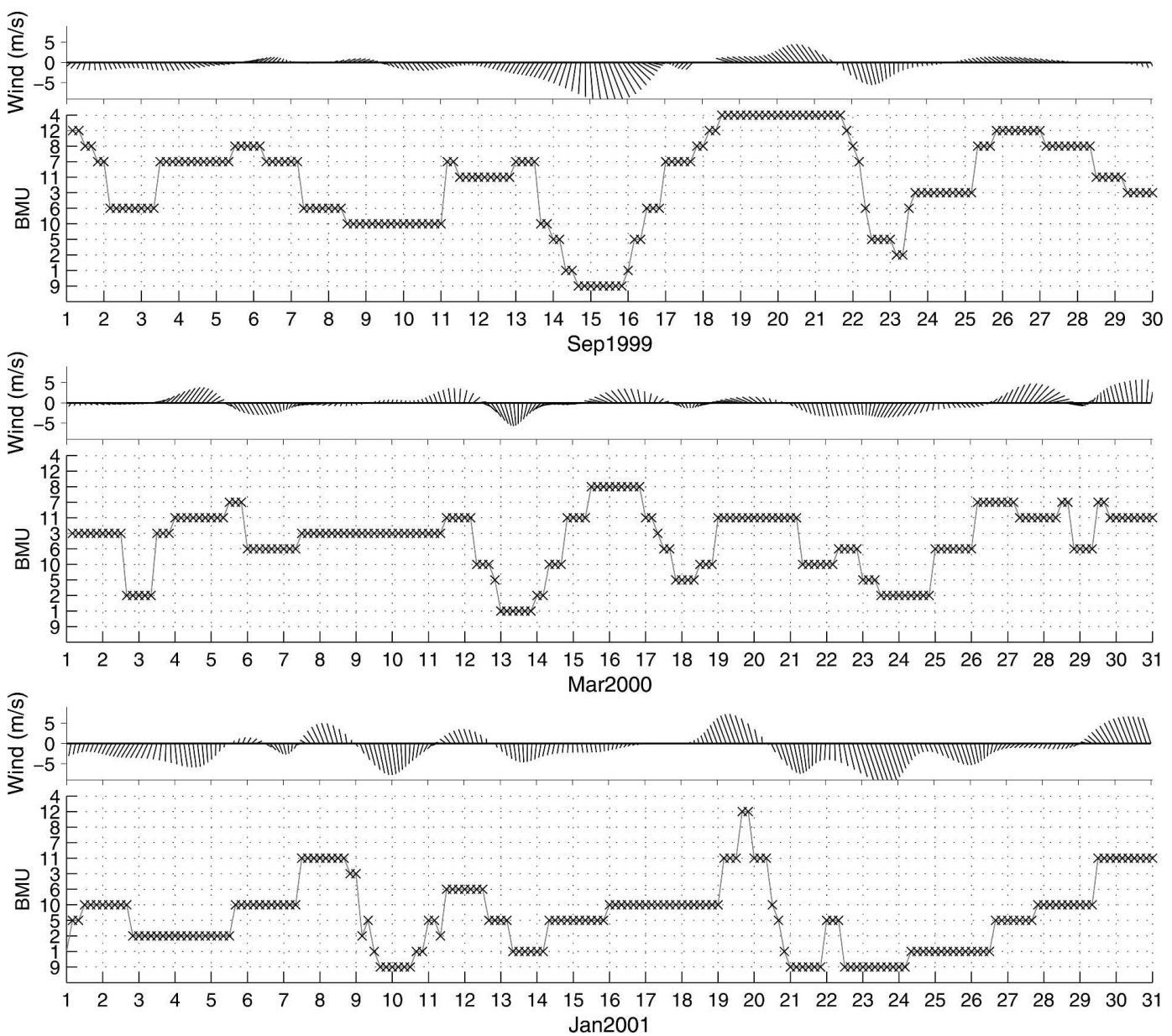

FIG. 5. Time series of Venice winds and the BMU for a 3-month interval.

Among the upwelling and downwelling structures, two extreme current patterns (units 9 and 4), occur with along-shelf current core located around the $30-\mathrm{m}$ isobath and speeds exceeding $26 \mathrm{~cm} \mathrm{~s}^{-1}$. These extreme current patterns correspond to the most severe synoptic weather events, with frequencies of occurrence of $1 \%-$ $3 \%$. The strong downwelling structure (unit 4) appears mostly in September-October of each year (Fig. 4, bottom panel), associated with tropical storms; an example being the 19-22 September 1999 Tropical Storm Harvey event (Fig. 5, top panel). The strong upwelling structure (unit 9) appears in autumn and winter because of the passage of strong extratropical cold fronts, and also on the trailing side of tropical storms. Examples are the 21-24 January 2001 upwelling event by a cold front (Fig. 5, bottom panel), and the 14-15 September 1999 event by Hurricane Floyd (Fig. 5, top panel).

Except for these two extreme units, flow asymmetries are found between the upwelling (units 1,2, and 5) and downwelling (units 8 and 12) structures. In addition to the asymmetries in intensity and across-shelf extent of the coastal jet shown by Liu and Weisberg (2005b) here the coastal jet core is found subsurface for upwelling versus at the surface for downwelling. Also, while weak, the across-shelf flows have opposite signs near the surface and near the bottom at the $10-\mathrm{m}$ isobath for upwelling, whereas they vanish at the 10-m isobath for downwelling; that is, across-shelf transport for upwelling occurs across the entire inner shelf, whereas it is inhibited in the shallower water (at the $10-\mathrm{m}$ isobath) for downwelling. These asymmetries, consistent with the findings of Weisberg et al. (2001), cannot be seen in a single EOF mode.

To better appreciate the utility of the SOM in identifying patterns and their evolution consider zoom views for the three months (September 1999, March 2000, and January 2001) shown in Fig. 5. From the BMU time series we see the preference for numbers 9 and 1 , and the adjacent units when the local winds are upwelling favorable (directed southward), versus number 4 and 12 and their adjacent units when the winds 
are downwelling favorable (directed northward). Note that the BMU time series evolution is coherent with the local winds, consistent with the winds being the main driving force for the inner shelf current variability over the synoptic weather band.

\section{2) Seasonal variability}

The SOM analysis of the 2-day low-pass-filtered data also demonstrates a seasonal variation as seen in the BMU time series (Fig. 4, bottom panel). While not shown, we applied the same SOM analysis procedure to 15-day low-pass-filtered data and found upwelling structures to prevail in autumn through spring months and downwelling structures to prevail in summer months.

These SOM and EOF results on the seasonal cycle agree with several previous analyses (Weisberg et al. 1996, 2005; He and Weisberg 2002, 2003; Liu and Weisberg 2005b; Weisberg et al. 2005). Hovmöller plots of the near surface inner shelf currents (Fig. 6) also show this clearly. From October to March the surface currents tend to be southeastward, whereas following a transition in May, they tend to be northwestward from June through September. Focusing on the 20-m isobath, for which we have the longest record, Fig. 7 shows a 6-yr climatology for the along-shelf and across-shelf current profiles. In the across-shelf direction a twolayer structure is seen with near bottom onshore flow and near surface offshore flow throughout the autumn through spring months (October-May), and in the along-shelf direction the currents tend to be southeastward from autumn to spring and northwestward in summer. The spring transition takes longer than the autumn transition, as also evidenced in temperature data (Virmani and Weisberg 2003), because of convective overturning in autumn versus more gradual heating in spring. These results are in contrast with statements by Ohlmann and Niiler (2005) who contend that the seasonal variations in the WFS surface currents are not pronounced. We attribute this to insufficient sampling on the WFS by the drifters.

\section{Across-shelf structure from hydrographic data}

Autumn/winter and summer across-shelf distributions of the temperature, salinity, and baroclinic geostrophic currents are shown in Fig. 8 for both the Sarasota and Tampa Bay transects. The autumn/winter (summer) composites are obtained by averaging the hydrographic data (and the relative geostrophic velocity) from October to March (June-September). The relative geostrophic velocities are first calculated using the hydrographic data in each cruise based on Eq. (10), with zero reference levels at the bottom, and then averaged over the specific months.

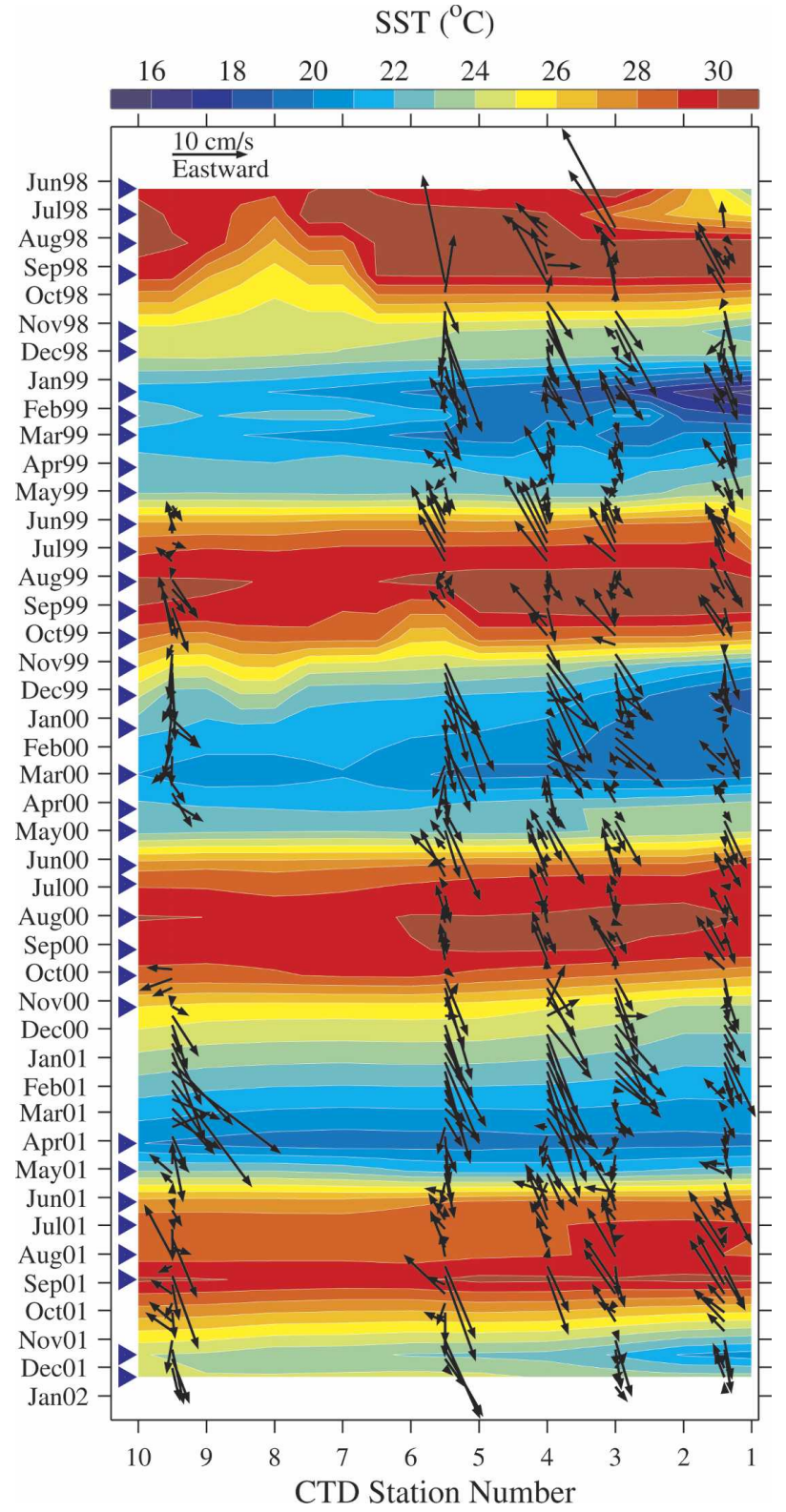

FIG. 6. Hovmöller plot of the near-surface temperature sampled by CTD along the Tampa Bay transect and the 30-day low-passfiltered ADCP near-surface currents sampled along the Sarasota transect. Blue triangles indicate the hydrographic cruises: CTD station 1 is closest to shore, and station 10 is at the $50-\mathrm{m}$ isobath.

In autumn/winter the shelf waters are colder and fresher near the coast than offshore. The higher salinity water found offshore tends to move onshore along the bottom and the lower salinity water found near shore tends to move offshore near the surface, indicating an upwelling circulation structure consistent with the along-shelf baroclinic geostrophic currents being directed southeastward. The baroclinic current core is located between the 25-35-m isobaths (or 45-65 km off- 

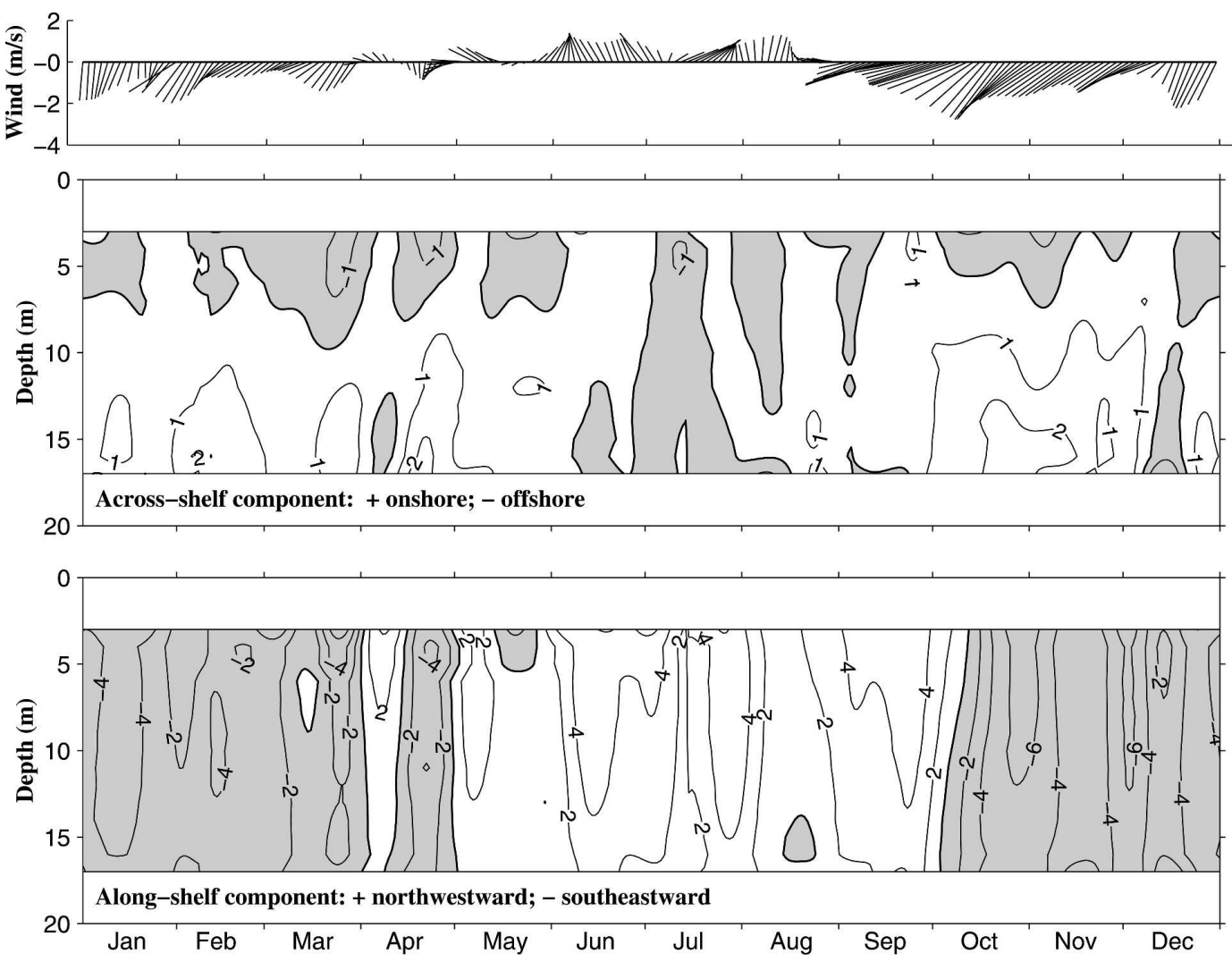

FIG. 7. Climatological means of the 20-day low-pass-filtered winds (at the NOAA Buoy 42036) and currents (at the EC4 mooring). The wind time series span 1994-2003, and currents span July 1998-February 2004.

shore from the coast) along the Sarasota transect, which has about the same location as those derived by the EOF and SOM.

In summer, strong stratification is found in the temperature structure that is due to increased insolation and decreased wind mixing. Surface temperature exceeds $28^{\circ} \mathrm{C}$, with the highest temperature near the coast, and the downward bowing of the isotherms near the bottom is consistent with a downwelling flow structure. An increase in salinity is due to evaporation, but also noted are lower salinity near surface waters offshore. This is attributed to waters of Mississippi River (and other northern river) origin that regularly flow along the shelf break and midshelf (e.g., Gilbes et al. 1996; He and Weisberg 2002) in spring and summer. Nearer to shore the baroclinic currents in summer are weaker and generally northwestward, consistent with the ADCP data.

\section{Across-shelf sea surface height estimates}

A method to combine the velocity, hydrography, and wind data across the shelf for the purpose of estimating
SSH was proposed in section 3b. According to Eq. (9), the across-shelf SSH distribution over synoptic and longer time scales may be estimated from the acrossshelf distributions of the along-shelf vertically averaged (barotropic) and baroclinic currents and the acrossshelf wind stress component.

\section{a. Time scales longer than 15 days}

\section{1) Relative sea surface height ACROSS THE INNER SHELF}

The depth-averaged currents are obtained from velocity profile data, low-pass filtered to exclude oscillations on time scales shorter than 15 days, subsampled daily and rotated to the along-shelf direction. These barotropic currents at the five mooring sites are integrated in the across-shelf direction from the 50-m isobath to the near shore to produce the $\eta_{b}$ contribution to the $\mathrm{SSH}$ relative to the $50-\mathrm{m}$ isobath according to Eq. (8a). The $\eta_{b}$ values at the six integration points are then linearly interpolated onto 10 locations equally distributed from the 50 - to the $10-\mathrm{m}$ isobaths along the Sarasota transect. We similarly calculated the relative 


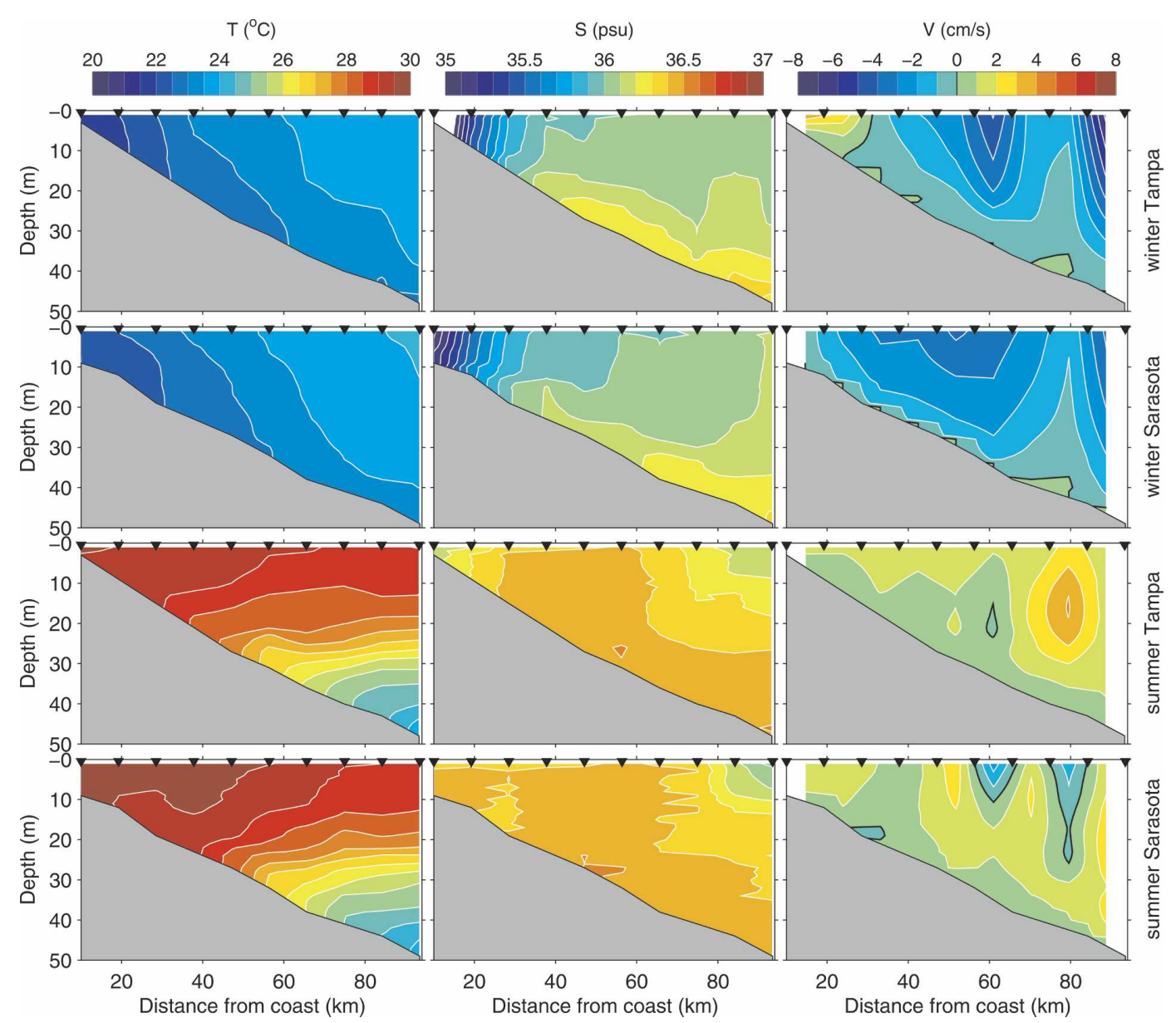

FIG. 8. Average across-shelf structures of (left) temperature, (middle) salinity, and (right) baroclinic geostrophic current along the Tampa Bay and Sarasota transects during (top) the winter and (bottom) summer seasons. Zero-velocity levels are set to be on the bottom in the baroclinic geostrophic current calculations. Winter structures are averaged from October to March, and summer structures from June through September. The small solid triangles designate the CTD locations.

SSH distribution due to the baroclinic currents $\left(\eta_{c}\right)$ from the monthly hydrographic data according to Eq. (8b). These monthly $\eta_{c}$ values are interpolated to form a daily time series for addition to $\eta_{b}$. To calculate $\eta_{w}$ we begin with 15-day low-pass filtered wind stress vectors, daily subsampled, and rotated $27^{\circ}$ clockwise to the across-shelf direction. The across-shelf wind stress component is then used to estimate $\eta_{w}$ at the 10 points offshore from Sarasota according to Eq. (8c). The three SSH components $\left(\eta_{b}, \eta_{c}, \eta_{w}\right)$ are then summed together to form a total SSH distribution relative to the 50-m isobath. We note that $\eta_{c}$ may also be estimated from the vertical shears of the along-shelf velocity according to Eq. (9). With $\eta_{c}$ by hydrography (current shears) denoted by $\eta_{c 1}\left(\eta_{c 2}\right)$ the results are shown in Fig. 9, including each of the individual terms and their sums: $\eta_{1}=\eta_{b}+\eta_{c 1}+\eta_{w}$ and $\eta_{2}=\eta_{b}+\eta_{c 2}+\eta_{w}$. In general the SSH gradient is directed onshore during autumn through spring (October to May) and offshore during summer (June through September). These seasonal SSH variations are consistent with the EOF and SOM velocity analyses. As expected, the depthaveraged (barotropic) currents dominate the SSH gradient variations across the inner shelf. The across-shelf wind stress modifies the SSH to a lesser extent, mainly over the shallowest region in winter. The baroclinic currents contribute constructively in the SSH seasonal variation; that is, $\eta_{c}$ values at the coast are lower (higher) than those at the 50-m isobath in winter (summer).

We note that $\eta_{c}$ values calculated by the two methods do not agree in some months in Fig. 9. The hydrographic data have higher spatial resolution in the across-shelf direction, but are sampled monthly and with some months absent data (Fig. 2), while the current data have higher temporal resolution, but are 

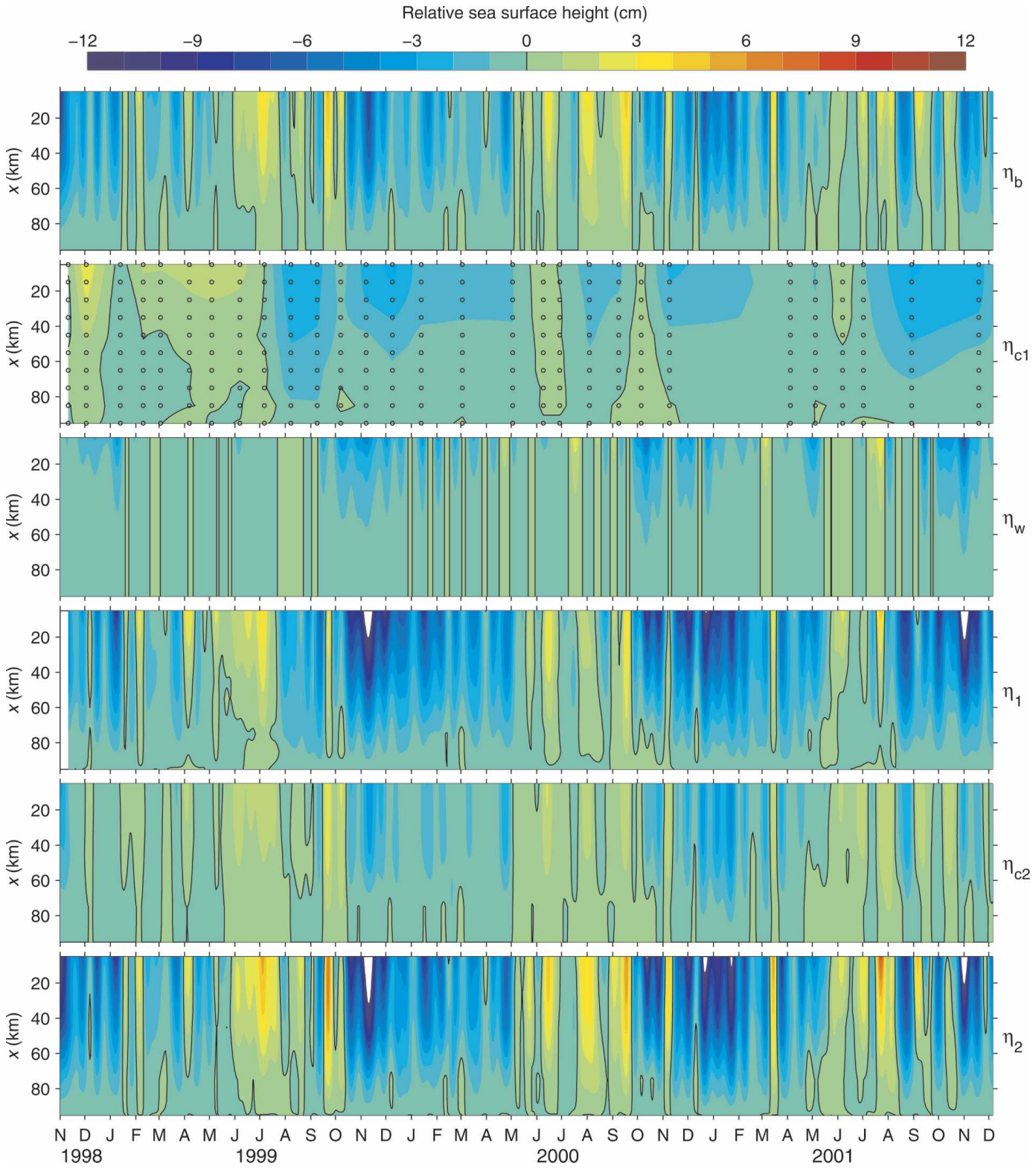

FIG. 9. SSH estimates relative to that at the 50-m site as a function of time and distance from coast ( $x$ ). (top to bottom) The SSH components due to the barotropic currents $\left(\eta_{b}\right)$, the baroclinic currents $\left(\eta_{c l}\right.$, estimated from the hydrographic data that are designated by the small open circles), and the across-shelf wind stress $\left(\eta_{w}\right)$; the total relative SSH $\left(\eta_{1}=\eta_{b}+\eta_{c 1}+\eta_{w}\right)$; the SSH component due to baroclinic currents ( $\eta_{c 2}$, estimated from the velocity vertical shears); and the total relative SSH $\left(\eta_{2}=\eta_{b}+\eta_{c 2}+\eta_{w}\right)$, respectively. All of the time series are 15-day low-pass filtered except the hydrographic data (and hence $\eta_{c l}$ ).

sparser in space. More observations (with higher resolutions in space and time) would improve the analysis, but the general features are consistent with one another.

\section{2) Absolute sea surface height}

The SSH variation in Fig. 9 are relative to the $50-\mathrm{m}$ isobath. If the absolute SSH at any one of the $10 \mathrm{com}$ - putation points is known, then the absolute SSH values along the whole transect (10 points) can be calculated by simply adding back the offset between absolute and relative SSH at that point. The relative SSH at the shallowest computation point $(\eta)$ and the coastal sea level at St. Petersburg $(h)$ are shown in the top panel of Fig. 10. Here the coastal sea level is also 15-day low-pass filtered and adjusted for the inverted barometer effect 

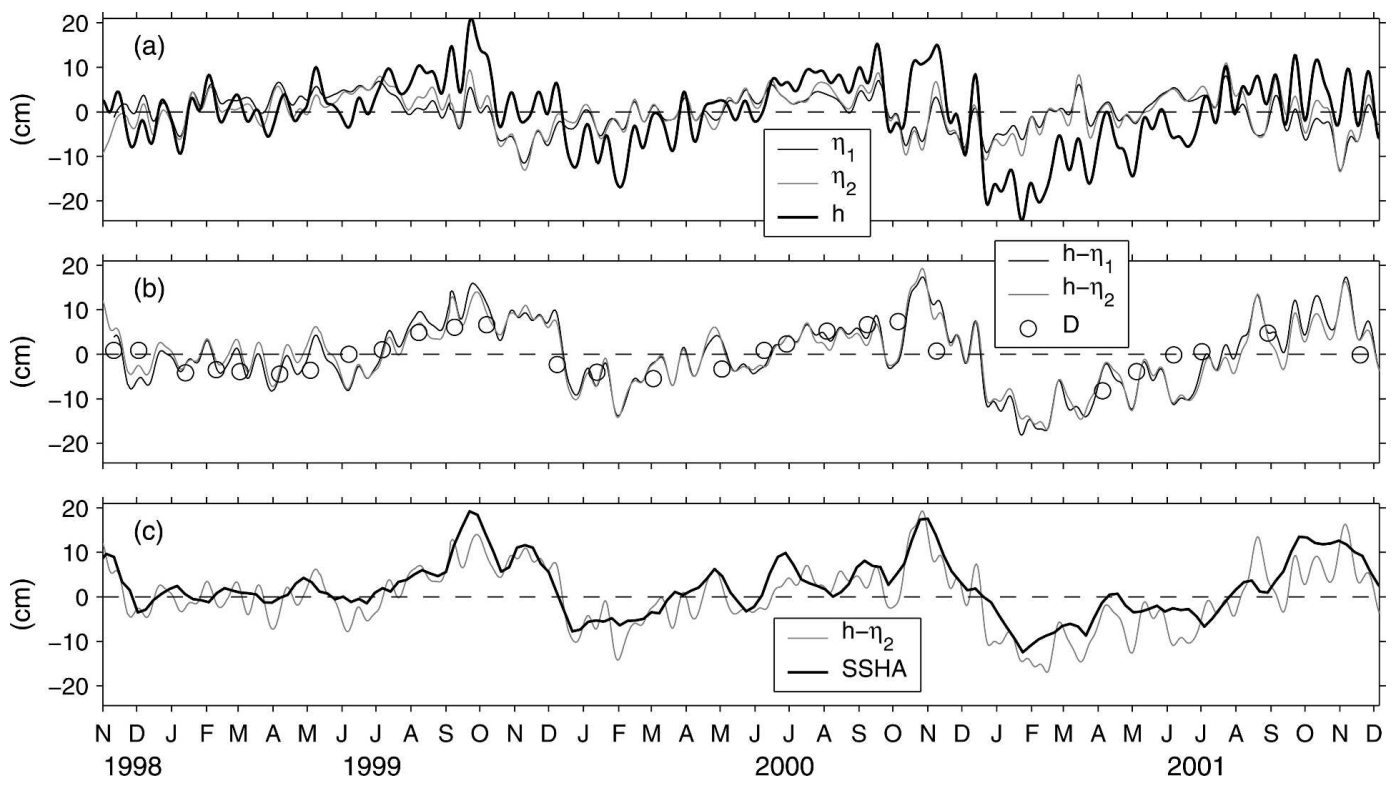

FIG. 10. Comparisons of the SSH estimates at low frequency (15-day low-pass filtered). (a) The total relative SSH $(\eta)$ estimated at the 10-m isobath and the sea level $(h)$ observed at St. Petersburg, where $\eta_{1}$ and $\eta_{2}$ are the two estimates of the total relative SSH differing by whether the baroclinic part is estimated from hydrographic data and from current (vertical) shear, respectively. (b) Estimated SSH $(h-\eta)$ and the geopotential height $(D)$ calculated from the hydrographic data at the 50-m isobath. (c) Estimated SSH $(h-\eta)$ and the altimetry SSH anomaly sampled from the 50-m isobath station.

(using the air pressure at Venice) since we had set the atmospheric pressure equal to zero in our derivation of Eq. (8). Assuming that the absolute SSH at the shallowest computation point may be approximated by the adjusted sea level at St. Petersburg, the offset between these two variables $(h-\eta)$ can be used to estimate the absolute SSH elsewhere. This offset can be regarded as the absolute SSH at the initial integration point (i.e., at the 50-m isobath). We note that despite the two methods for estimating $\eta_{1}$ and $\eta_{2}$, the estimated absolute $\mathrm{SSH}$ at the 50-m isobath is very similar for both.

The variations at the 50-m isobath are larger than those over the inner shelf. Some of this may be local and due to a seasonal steric effect, while some may be related to deeper water influences. We estimate the local steric effect through the geopotential height $D$ at the $50-\mathrm{m}$ isobath station calculated from the hydrographic data according to

$$
D\left(p_{1}, p_{2}\right)=\frac{1}{g} \int_{p_{1}}^{p_{2}} \delta(T, S, p) d p,
$$

where $p_{1}$ and $p_{2}$ are two reference pressure levels, $\delta, T$, $S$, and $p$ are specific volume anomaly, temperature, salinity, and pressure, respectively. The result is shown against the estimated absolute $\mathrm{SSH}$ at the 50-m isobath in Fig. 10b. The estimated SSH compares well to the geopotential height during the three years, which means a portion of the 50-m SSH variation in the lowfrequency band is induced locally by the steric height changes on the shelf.

We also compare the absolute SSH estimates at the $50-\mathrm{m}$ isobath with the available satellite altimetry data. We used the gridded sea level anomalies $\left(13^{\circ} \times 1 / 3^{\circ}\right.$ on a Mercator grid) merged from multisatellite altimetry sensors (TOPEX/Poseidon or Jason-1 + ERS-1/2 or Envisat) distributed by AVISO. By sampling a grid point nearest to mooring EC2 $(50 \mathrm{~m})$ site, we overlay the SSH anomaly by satellite altimetry on the SSH estimates in Fig. 10c. The comparison is good. Note the SSH estimates are 15-day low-pass filtered and daily subsampled, and the altimetry time series are sampled in 7-day intervals.

\section{b. Synoptic time scales}

Since the SSH equations are derived from the momentum balance over the synoptic weather and longer time scales, it is informative to check their validity at shorter time scales. By using a two-day low-pass filter on the velocity, sea level, and air pressure time series, and the same integration and interpolation procedures as before, we estimate the absolute $\mathrm{SSH}$ at the $50-\mathrm{m}$ isobath across the entire subtidal band (Fig. 11). Since the procedures are linear the results overlay well, and 


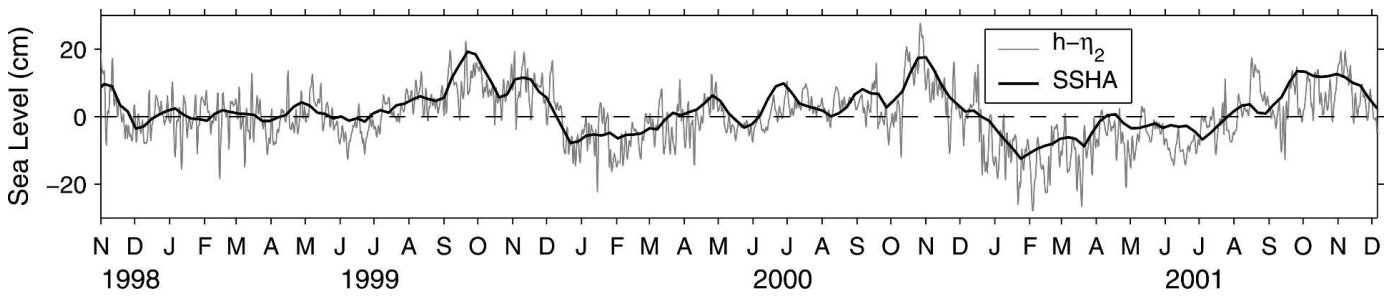

FIG. 11. Similar to Fig. 10c, but for the 2-day low-pass-filtered $\eta_{2}$.

they show the relative variances between the synoptic weather and seasonal time scales.

Last, it is instructive to consider the synoptic weather band by itself by bandpass filtering the time series prior to the SSH estimation procedure. The results are shown in Fig. 12 for the band of 2-15 day. Zooming in for the period July-December 2001 we see that the $10-\mathrm{m}$ isobath relative SSH estimates are highly correlated with the St. Petersburg sea level, the EC5 (10-m isobath) bottom pressure, and the local winds. This suggests that the primarily wind-driven inner shelf circulation is mainly responsible for the coastal sea level variation on the synoptic time scale. We note that the estimated SSH amplitudes are closer to those of the EC5 bottom pressure and smaller than those at the St. Petersburg. This may be explained by the following two factors. First, the St. Petersburg tide gauge is located midway up Tampa Bay so it experiences additional setup/down by local wind effects within the bay. Second, the synopticscale variation occurring offshore of the 50-m isobath are not taken into account in these estimates. Actually, the absolute $\mathrm{SSH}$ at the $50-\mathrm{m}$ isobath, estimated as the difference between the observed absolute $(h)$ and estimated relative $\mathrm{SSH}(\eta)$ at the EC5 (Fig. 12, third panel), is also correlated with the observed coastal sea levels and the winds. The decrease of the SSH amplitudes from the coast (St. Petersburg), offshore to the 10 - and $50-\mathrm{m}$ isobaths is consistent with previous findings (Marmorino 1983b; Mitchum and Clarke 1986a). The fact that the agreement is so good at the EC5 bottom pressure gauge suggest that most of the inner shelf dynamical adjustment does indeed occur inshore of the $50-\mathrm{m}$ isobath, and this is consistent with the model dynamics analysis presented by Li and Weisberg (1999b).

By zooming in on a subset of the analysis Fig. 12 also shows how the three SSH components are additive to the total relative $\mathrm{SSH}$ estimates. For the full record length, the standard deviations of $\eta_{b}, \eta_{w}$, and $\eta_{c}$ are 2.6, 1.8 , and $1.2 \mathrm{~cm}$, respectively. Thus, among the three dynamical variables, the along-shelf barotropic currents make the largest contribution to the inner shelf sea level variations (included in Mitchum and Clarke 1986a), the across-shelf wind stress is of secondary im- portance, and the along-shelf baroclinic currents have the smallest effect. Cragg et al. (1983) reported that WFS sea level response was a maximum for along-shelf winds; across-shelf winds did not produce sea level fluctuations that were statistically reliable. Our analysis shows that the across-shelf winds also play an important role in changing inner shelf $\mathrm{SSH}$, especially during strong weather events (Fig. 12, bottom panel).

\section{Summary and discussions}

Using velocity profile time series from an across-shelf moored array spanning the interval September 1998 to December 2001, we described the across-shelf structures of the inner WFS current variability on synoptic and longer time scales. From two-day, low-pass-filtered data, a coherent wind-driven coastal upwelling/downwelling structure was revealed by the first mode EOF: an along-shelf coastal jet with a current core located around the 25-30-m isobaths, and oppositely directed across-shelf flows at the near surface and near bottom levels, consistent Ekman-geostrophic inner shelf dynamics (e.g., Li and Weisberg 1999b; Weisberg et al. 2000). Additional important details were extracted by the SOM: strong upwelling and downwelling flow structures associated with extreme weather forcing, moderate, asymmetric upwelling and downwelling flow structures driven by moderate weather forcing, and a set of transitional structures with weak currents. The variations of these structures are coherent with local winds on synoptic weather time scales. On seasonal and longer time scales, the circulation is predominantly upwelling during autumn through spring months (October-April) and downwelling during summer months (June-September). These upwelling/downwelling across-shelf structures provide observational evidence, as well as new insights, to the schematics of coastal upwelling/downwelling regimes of Huyer (1990). They also have important implications for the transports of nutrients and other water properties across the shelf.

The coherent seasonal variation of the WFS currents, as revealed by the EOF, the SOM, a Hovmöller plot of the near surface currents, and a 6-yr climatology of current profiles at the $20-\mathrm{m}$ isobath, agrees with previ- 

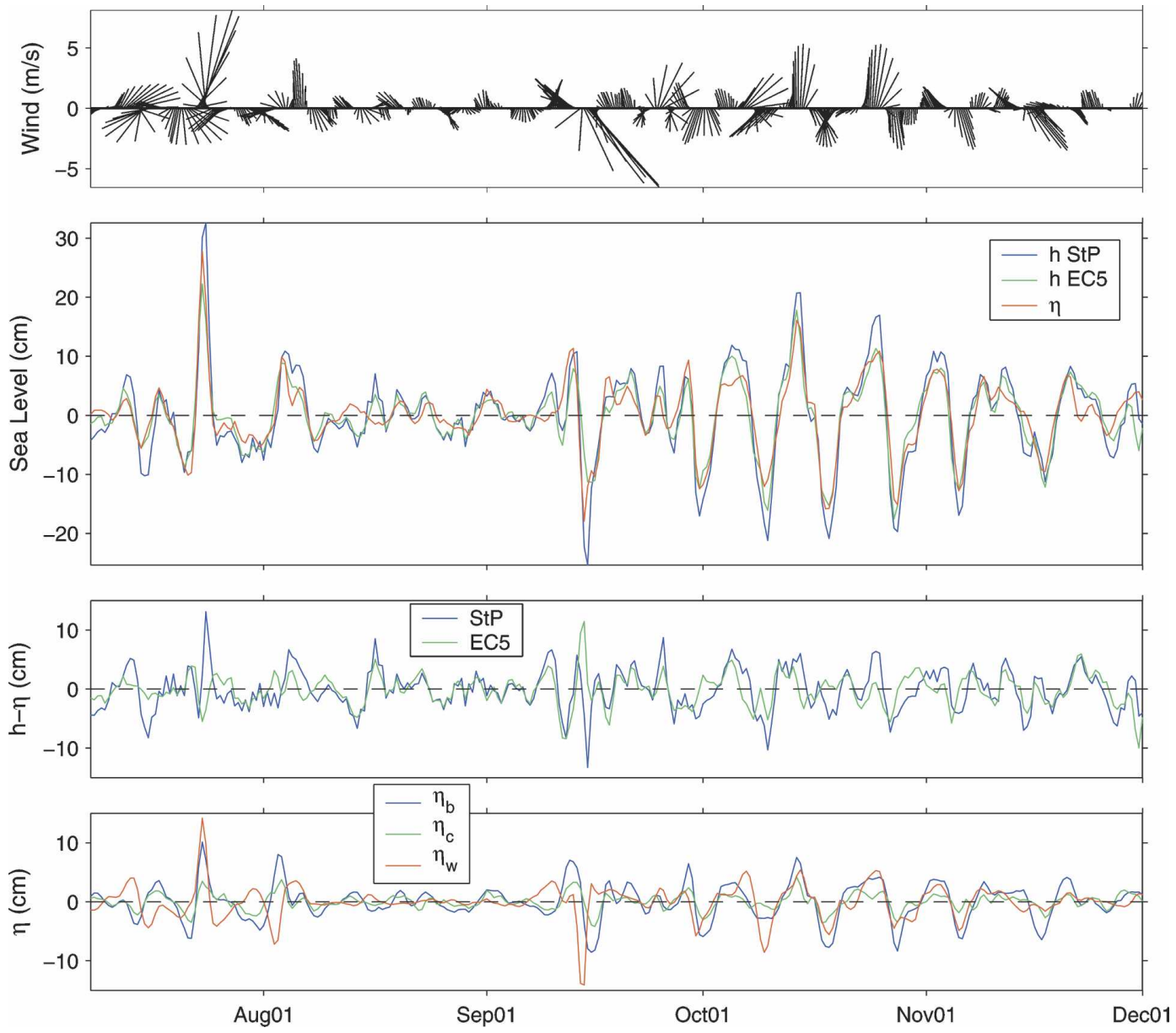

FIG. 12. (top) Time series of wind and SSH estimates at the synoptic weather band (2-day $\sim 15$-day bandpass filtered). (upper middle) The total relative SSH $(\eta)$ estimated at the $10-\mathrm{m}$ isobath and the sea level $(h)$ observed at St. Petersburg and mooring EC5 (converted from bottom pressure records). (lower middle) The difference between the observed and estimated SSH $(h-\eta)$. (bottom) The three SSH components estimated at the 10-m isobath, due to barotropic currents $\left(\eta_{b}\right)$, baroclinic currents $\left(\eta_{c}\right)$, and across-shelf wind stress $\left(\eta_{w}\right)$, respectively.

ous data analysis and numerical modeling results (Weisberg et al. 1996; He and Weisberg 2002, 2003; Liu and Weisberg 2005b; Weisberg et al. 2005). We therefore disagree with the Ohlmann and Niiler (2005) statement that the seasonal variations of the WFS surface currents are not pronounced, and we attribute this difference in dataset interpretation to insufficient sampling by drifters on the WFS.

On seasonal and longer time scales, the asymmetry in upwelling/downwelling structures is consistent with an asymmetry in the wind forcing. Winter upwelling favorable winds are much stronger than summer downwelling winds, as shown in Figs. 2 and 7. On the synoptic weather scale, the asymmetry is also due to stratification. Weisberg et al. (2001) using model twin experiments, one with and the other without stratification, explained the observed WFS response asymmetry as a consequence of thermal wind effects on the bottom Ekman layer. Increased mixing for extreme events would therefore tend to mitigate this effect. This synoptic weather-scale asymmetry, with larger upwelling than downwelling responses, is consistent with the works of Weatherly and Martin (1978), Trowbridge and Lentz (1991), MacCready and Rhines (1991), and Garrett et al. (1993) when consideration is given to the process of Ekman-geostrophic spinup. With regard to a streamwise vorticity balance, by adding constructively (destructively) with planetary vorticity tilting by the sheared, along-shelf jet, buoyancy torque enhances (decreases) the dissipation required in the bottom Ekmanlayer underupwelling (downwelling). This results in a larger upwelling response that extends farther offshore.

WFS circulation is driven by a combination of local and remote forcing (Weisberg and He 2003). Coastal 
sea level variations can also be apportioned that way; that is, by the local dynamical response of the inner shelf circulation to local meteorological forcing and by SSH variations occurring farther offshore and as manifest at the 50-m isobath. The local dynamical response can further be partitioned into three parts; that is, the $\mathrm{SSH}$ responses due to the along-shelf depth-averaged (barotropic) currents, the baroclinic currents, and the across-shelf wind stress. On long time scales, the offshore SSH change dominates, and a significant portion of the $50-\mathrm{m}$ isobath SSH variation is due to the local steric height changes, whereas on synoptic weather time scales the inner shelf wind-driven circulation responses are controlling. Among the three dynamical variables, the barotropic currents make the largest contribution to the inner shelf SSH variations, the acrossshelf wind stress is the secondary contributor, and the baroclinic currents make the smallest contribution.

On long time scales, the SSH estimated at the 50-m isobath as the residual between the coastal sea level and the inner shelf dynamical responses compared well to satellite altimetry, thus providing a basis for calibrating satellite altimetry on the shelf. An error analysis of the largest SSH component (barotropic contribution) show that this approach is feasible. Equation (8a) can be approximated as $\Delta \eta=L f g^{-1} \Delta v$, where $L$ is the acrossshelf distance. For the WFS inner shelf, where $L=90$ $\mathrm{km}, f=0.66 \times 10^{-4} \mathrm{~s}^{-1}$, and $g=10 \mathrm{~m} \mathrm{~s}^{-2}$, a $\Delta v$ of $2 \mathrm{~cm}$ $\mathrm{s}^{-1}$ can only induce a $\Delta \eta$ of $1 \mathrm{~cm}$, which is smaller than accuracy $(2 \mathrm{~cm})$ of the GPS altimetry (Treuhaft et al. 2001). On synoptic time scales, the SSH estimates are coherent with the bottom pressure records, coastal sea level, and local winds. So while seasonal SSH variations are largely of offshore origin, at synoptic weather scales these are primarily by the inner shelf dynamical adjustments that occur inshore of about the $50-\mathrm{m}$ isobath $(\mathrm{Li}$ and Weisberg 1999b).

Acknowledgments. Support was provided by the Office of Naval Research, Grants N00014-05-1-0483 and N00014-02-1-0972. The second of these, for the Southeast Atlantic Coastal Ocean Observing System (SEACOOS), is administered by UNC under task order 3-12110-10. The success of our moored velocity program is largely owed to R. Cole, J. Law, and C. Merz, with J. Donovan, V. Subramanian, and D. Mayer assisting with real time acquisition, editing and analyses. The hydrographic data were provided by G. Vargo and C. Heil. The wind and coastal sea level were provided by NOAA/NDBC and NOAA/NOS, respectively. The altimeter products were produced by SSALTO/ DUACS as part of the Environment and Climate European Enact project (EVK2-CT2001-00117) and dis- tributed by AVISO, with support from CNES. The SOM MATLAB Toolbox was by E. Alhoniemi, J. Himberg, J. Parhankangas, and J. Vesanto.

\section{REFERENCES}

Ainsworth, E. J., and S. F. Jones, 1999: Radiance spectra classification from the ocean color and temperature scanner on ADEOS. IEEE Trans. Geosci. Remote Sens., 37, 1645-1656.

Ambroise, C., G. Seze, F. Badran, and S. Thiria, 2000: Hierarchical clustering of self-organizing maps for cloud classification. Neurocomputing, 30, 47-52.

Blaha, J., and W. Sturges, 1981: Evidence for wind-forced circulation in the Gulf of Mexico. J. Mar. Res., 39, 771-833.

Bonnefond, P., P. Exertier, O. Laurain, Y. Menard, A. Orsoni, G. Jan, and E. Jeansou, 2003: Absolute calibration of Jason-1 and TOPEX/Poseidon altimeters in Corsica. Mar. Geod., 26, 261-284.

Born, G. H., M. E. Parke, P. Axelrad, K. L. Gold, J. Johnson, K. W. Key, D. G. Kubitschek, and E. J. Christensen, 1994: Calibration of the TOPEX altimeter using a GPS buoy. $J$. Geophys. Res., 99 (C12), 24 517-24 526.

Brink, K. H., 1983: The near-surface dynamics of coastal upwelling. Progress in Oceanography, Vol. 12, Pergamon Press, 223-257.

- D. Halpern, and R. L. Smith, 1980: Circulation in the Peruvian upwelling system near $15^{\circ}$ S. J. Geophys. Res., 85, 40364048.

$\_, \ldots$, A. Huyer, and R. L. Smith, 1983: The physical environment of the Peruvian upwelling system. Progress in Oceanography, Vol. 12, Pergamon Press, 285-305.

Cavazos, T., 2000: Using self-organizing maps to investigate extreme climate events: An application to wintertime precipitation in the Balkans. J. Climate, 13, 1718-1732.

Cheney, R., L. Miller, R. Agreen, N. Doyle, and J. Lillibridge, 1994: TOPEX/Poseidon: The 2-cm solution. J. Geophys. Res., 99 (C12), 24 555-24 564.

Cheng, P., and R. E. Wilson, 2006: Temporal variability of vertical nontidal circulation pattern in a partially mixed estuary: Comparison of self-organizing map and empirical orthogonal functions. J. Geophys. Res., 111, C12021, doi:10.1029/ 2005JC003241.

Christensen, E. J., and Coauthors, 1994: Calibration of TOPEX/ Poseidon at Platform Harvest. J. Geophys. Res., 99, 24 46524486.

Cragg, J., G. Mitchum, and W. Sturges, 1983: Wind-induced seasurface slopes on the West Florida shelf. J. Phys. Oceanogr., 13, 2201-2212.

Csanady, G. T., 1979: The pressure field along the western margin of the North Atlantic. J. Geophys. Res., 84 (C8), 4905-4915.

Davis, R. E., 1976: Predictability of sea surface temperature and sea level pressure anomalies over the North Pacific Ocean. $J$. Phys. Oceanogr., 6, 249-266.

Douglas, B. C., D. C. McAdoo, and R. E. Cheney, 1987: Oceanographic and geophysical applications of satellite altimetry. Rev. Geophys., 25, 875-880.

Fu, L.-L., and R. E. Cheney, 1995: Application of satellite altimetry to ocean circulation studies: 1987-1994. Rev. Geophys., 33, 213-224.

— E. J. Christensen, C. A. Yamarone Jr., M. Lefebvre, Y. Ménard, M. Dorrer, and P. Escudier, 1994: TOPEX/Poseidon mission overview. J. Geophys. Res., 99, 24 369-24 382. 
Garrett, C., P. MacCready, and P. Rhines, 1993: Boundary mixing and arrested Ekman layers: Rotating stratified flow near a sloping boundary. Annu. Rev. Fluid Mech., 25, 291-323.

Gilbes, F., C. Tomas, J. J. Walsh, and F. E. Müller-Karger, 1996: An episodic chlorophyll plume on the west Florida shelf. Cont. Shelf Res., 16, 1201-1224.

Haines, B. H., D. Dong, G. H. Born, and S. K. Gill, 2003: The Harvest experiment: Monitoring Jason-1 and TOPEX/ Poseidon from a California offshore platform. Mar. Geod., 26, 239-259.

Halper, F. B., and W. W. Schroeder, 1990: The response of shelf waters to the passage of tropical cyclones-Observations from the Gulf of Mexico. Cont. Shelf Res., 10, 777-793.

Hardman-Mountford, N. J., A. J. Richardson, D. C. Boyer, A. Kreiner, and H. J. Boyer, 2003: Relating sardine recruitment in the Northern Benguela to satellite-derived sea surface height using a neural network pattern recognition approach. Progress in Oceanography, Vol. 59, Pergamon Press, 241255.

He, R., and R. H. Weisberg, 2002: West Florida shelf circulation and temperature budget for the 1999 spring transition. Cont. Shelf Res., 22, 719-748.

$\longrightarrow$, and - 2003: West Florida shelf circulation and temperature budget for the 1998 fall transition. Cont. Shelf Res., 23, 777-800.

Hewitson, B. C., and R. G. Crane, Eds., 1994: Neural Nets: Applications in Geography. Kluwer Academic, 194 pp.

$\longrightarrow$, and —, 2002: Self-organizing maps: Applications to synoptic climatology. Climate Res., 22, 13-26.

Hong, Y., K. Hsu, S. Sorooshian, and X. Gao, 2005: Selforganizing nonlinear output (SONO): A neural network suitable for cloud patch-based rainfall estimation at small scales. Water Resour. Res., 41, W03008, doi:10.1029/2004WR003142.

_-, Y.-M. Chiang, Y. Liu, K.-L. Hsu, and S. Soroohian, 2006: Satellite-based precipitation estimation using watershed segmentation and growing hierarchical self-organizing map. Int. J. Remote Sens., 27 (23), 5165-5184.

Huyer, A., 1983: Coastal upwelling in the California Current system. Progress in Oceanography, Vol. 12, Pergamon Press, 259-284.

_ 1990: Shelf circulation. The Sea, B. LeMehaute and D. M. Hanes, Eds., Ocean Engineering Science, Vol. 9, John Wiley and Sons, 423-466.

Kaski, S., J. Kangas, and T. Kohonen, 1998: Bibliography of selforganizing map (SOM) papers: 1981-1997. Neural Comput. Surv., 1, 102-350.

Katz, E. J., A. Busalacchi, M. Bushnell, F. Gonzalez, L. Gourdeau, M. McPhaden, and J. Picaut, 1995: A comparison of coincidental time series of the ocean surface height by satellite altimeter, mooring, and inverted echo sounder. J. Geophys. Res., 100 (C12), 25 101-25 108.

Klinck, J. M., 1985: EOF analysis of central Drake Passage currents from DRAKE 79. J. Phys. Oceanogr., 15, 288-298.

Kohonen, T., 1982: Self-organized information of topologically correct features maps. Bio. Cyber., 43, 59-69.

_ 2001: Self-Organizing Maps. 3d ed. Springer Series in Information Sciences, Vol. 30, Springer-Verlag, 501 pp.

Kundu, P. K., and J. S. Allen, 1976: Some three-dimensional characteristics of low frequency current fluctuations near the Oregon coast. J. Phys. Oceanogr., 6, 181-199.

Lagerloef, G. S. E., and R. L. Bernstein, 1988: Empirical orthogonal function analysis of advanced very high resolution radi- ometer surface temperature patterns in Santa Barbara Channel. J. Geophys. Res., 93, 6863-6873.

_, G. T. Mitchum, R. B. Lukas, and P. P. Niiler, 1999: Tropical Pacific near-surface currents estimated from altimeter, wind, and drifter data. J. Geophys. Res., 104, 23 313-23 326.

Leloup, J. A., Z. Lachkar, J.-P. Boulanger, and S. Thiria, 2007: Detecting decadal changes in ENSO using neural networks. Climate Dyn., 28, 147-162.

Lentz, S. J., S. Elgar, and R. T. Guza, 2003: Observations of the flow field near the nose of a buoyant coastal current. J. Phys. Oceanogr., 33, 933-943.

Li, Z., and R. H. Weisberg, 1999a: West Florida shelf response to upwelling favorable wind forcing: Kinematics. J. Geophys. Res., 104, 13 507-13 527.

— , and _ 1999b: West Florida continental shelf response to upwelling favorable wind forcing 2. Dynamics. J. Geophys. Res., 104, 23 427-23 442.

Liu, Y., and R. H. Weisberg, 2005a: Momentum balance diagnoses for the west Florida shelf. Cont. Shelf Res., 25, 20542074.

— and $-2005 \mathrm{~b}$ : Patterns of ocean current variability on the west Florida shelf using the self-organizing map. J. Geophys. Res., 110, C06003, doi:10.1029/2004JC002786.

$\ldots, \ldots$, and R. He, 2006a: Sea surface temperature patterns on the west Florida shelf using growing hierarchical selforganizing maps. J. Atmos. Oceanic Technol., 23, 325-338.

,-- , and C. N. K. Mooers, 2006b: Performance evaluation of the self-organizing map for feature extraction. J. Geophys. Res., 111, C05018, doi:10.1029/2005JC003117.

, _ _ , and L. K. Shay, 2007a: Current patterns on the west Florida shelf from joint self-organizing map analyses of HF radar and ADCP data. J. Atmos. Oceanic Technol., 24, 702712.

,-- , and Y. Yuan, 2007b: Patterns of upper layer circulation variability in the South China Sea from satellite altimetry using the self-organizing map. Acta Oceanol. Sin., in press.

MacCready, P., and P. B. Rhines, 1991: Buoyant inhibition of Ekman transport on a slope and its effect on stratified spin-up. J. Fluid Mech., 223, 631-661.

Malmgren, B. A., and A. Winter, 1999: Climate zonation in Puerto Rico based on principal components analysis and an artificial neural network. J. Climate, 12, 977-985.

Marmorino, G. O., 1982: Wind-forced sea level variability along the West Florida shelf (winter, 1978). J. Phys. Oceanogr., 12, 389-405.

_ 1983a: Small-scale variations of the wind-driven coastal sea level response in the West Florida Bight. J. Phys. Oceanogr., 13, 93-102.

_ 1983b: Variability of current, temperature, and bottom pressure across the West Florida continental shelf, winter, 19811982. J. Geophys. Res., 88 (C7), 4439-4457.

Ménard, Y., E. Jeansou, and P. Vincent, 1994: Calibration of the TOPEX/Poseidon altimeters at Lampedusa: Additional results at Harvest. J. Geophys. Res., 99, 24 487-24 504.

Menkes, C., J.-P. Boulanger, and A. J. Busalacchi, 1995: Evaluation of TOPEX and basin-wide tropical ocean and global atmosphere-tropical atmosphere ocean sea surface topographies and derived geostrophic currents. J. Geophys. Res., 100 (C12), 25 087-25 100.

Meyers, S. D., E. M. Siegel, and R. H. Weisberg, 2001: Observations of currents on the west Florida shelf break. Geophys. Res. Lett., 28, 2037-2040. 
Mitchum, G. T., 1994: Comparison of TOPEX sea surface heights and tide gauge sea levels. J. Geophys. Res., 99, 24 541-24 553.

_ 1998: Monitoring the stability of satellite altimeters with tide gauges. J. Atmos. Oceanic Technol., 15, 721-730.

_- 2000: An improved calibration of satellite altimetric heights using tide gauge sea levels with adjustment for land motion. Mar. Geod., 23, 145-166.

— Florida shelf. J. Phys. Oceanogr., 12, 1310-1317.

—_, and A. J. Clarke, 1986a: The frictional nearshore response to forcing by synoptic scale winds. J. Phys. Oceanogr., 16, 934-946.

$\longrightarrow$, and - 1986b: Evaluation of frictional, wind forced long wave theory on the west Florida shelf. J. Phys. Oceanogr., 16, 1029-1037.

Mooers, C. N. K., C. A. Collins, and R. L. Smith, 1976: Dynamic structure of frontal zone in coastal upwelling region off Oregon. J. Phys. Oceanogr., 6, 3-21.

Niang, A., L. Gross, S. Thiria, F. Badran, and C. Moulin, 2003: Automatic neural classification of ocean colour reflectance spectra at the top of the atmosphere with introduction of expert knowledge. Remote Sens. Environ., 86, 257-271.

Niiler, P. P., 1976: Observations of low-frequency currents on the West Florida continental shelf. Mem. Soc. Roy. Sci. Liege, 6, 331-358.

Ohlmann, J. C., and P. P. Niiler, 2005: Circulation over the continental shelf in the northern Gulf of Mexico. Progress in Oceanography, Vol. 64, Pergamon Press, 45-81.

Oja, M., S. Kaski, and T. Kohonen, 2003: Bibliography of selforganizing map (SOM) papers: 1998-2001 addendum. Neural Comput. Surv., 3, 1-156.

Picaut, J., A. J. Busalacchi, M. J. McPhaden, L. Gourdeau, F. I. Gonzalez, and E. C. Hackert, 1995: Open-ocean validation of TOPEX/Poseidon sea level in the western equatorial Pacific. J. Geophys. Res., 100 (C12), 25 109-25 128.

Price, J. F., C. N. K. Mooers, and J. C. VanLeer, 1978: Observation and simulation of storm-induced mixed-layer deepening. J. Phys. Oceanogr., 8, 582-599.

Reusch, D. B., R. B. Alley, and B. C. Hewitson, 2007: North Atlantic climate variability from a self-organizing map perspective. J. Geophys. Res., 112, D02104, doi:10.1029/ 2006JD007460.

Richardson, A. J., M. C. Pfaff, J. G. Field, N. F. Silulwane, and F. A. Shillington, 2002: Identifying characteristic chlorophyll a profiles in the coastal domain using an artificial neural network. J. Plankton Res., 24, 1289-1303.

_ C. C. Risien, and F. A. Shillington, 2003: Using self-organizing maps to identify patterns in satellite imagery. Progress in Oceanography, Vol. 59, Pergamon Press, 223-239.

Risien, C. M., C. J. C. Reason, F. A. Shillington, and D. B. Chelton, 2004: Variability in satellite winds over the Benguela upwelling system during 1999-2000. J. Geophys. Res., 109, C03010, doi:10.1029/2003JC001880.

Samelson, R., and Coauthors, 2002: Wind stress forcing of the Oregon coastal ocean during the 1999 upwelling season. $J$. Geophys. Res., 107, 3034, doi:10.1029/2001JC000900.

Siegel, E. M., 1999: Currents observed across the west Florida continental shelf. M.S. thesis, Department of Marine Science, University of South Florida, 155 pp.

Silulwane, N. F., A. J. Richardson, F. A. Shillington, and B. A. Mitchell-Innes, 2001: Identification and classification of ver- tical chlorophyll patterns in the Benguela upwelling system and Angola-Benguela front using an artificial neural network. South Afr. J. Mar. Sci., 23, 37-51.

Smith, R., 1995: The physical processes of coastal ocean upwelling systems. Upwelling in the Ocean, C. Summerhayes et al., Eds., John Wiley and Sons, 40-64.

Teague, W. J., Z. R. Hallock, G. A. Jacobs, and J. L. Mitchell, 1995: Kuroshio sea surface height fluctuations observed simultaneously with inverted echo sounders and TOPEX/ Poseidon. J. Geophys. Res., 100 (C12), 24 987-24 994.

Tolbert, W. H., and G. G. Salsman, 1964: Surface circulation of the eastern Gulf of Mexico as determined by drift-bottled studies. J. Geophys. Res., 69, 223-230.

Treuhaft, R. N., S. T. Lowe, C. Zuffada, and Y. Chao, 2001: Twocm GPS altimetry over Crater Lake. Geophys. Res. Lett., 28, 4343-4346.

Trowbridge, J. H., and S. J. Lentz, 1991: Asymmetric behavior of an oceanic boundary layer above a sloping bottom. J. Phys. Oceanogr., 21, 1171-1185.

Verstraete, J.-M., and Y.-H. Park, 1995: Comparison of TOPEX/ Poseidon altimetry and in situ sea level data at Sao Tome Island, Gulf of Guinea. J. Geophys. Res., 100 (C12), 25129 25134.

Vignudelli, S., P. Cipollini, L. Roblou, F. Lyard, G. P. Gasparini, G. Manzella, and M. Astraldi, 2005: Improved satellite altimetry in coastal systems: Case study of the Corsica Channel (Mediterranean Sea). Geophys. Res. Lett., 32, L07608, doi:10.1029/2005GL022602.

Virmani, J. I., and R. H. Weisberg, 2003: Features of the observed annual ocean-atmosphere flux variability on the west Florida shelf. J. Climate, 16, 734-745.

Watson, C., R. Coleman, N. White, J. Church, and R. Govind, 2003: Absolute calibration of TOPEX/Poseidon and Jason-1 using GPS buoys in Bass Strait, Australia. Mar. Geod., 26, 285-304.

Weatherly, G. L., and P. J. Martin, 1978: On the structure and dynamics of the oceanic bottom boundary layer. J. Phys. Oceanogr., 8, 557-570.

, and D. Thistle, 1997: On the wintertime currents in the Florida Big Bend region. Cont. Shelf Res., 17, 1297-1319.

Weisberg, R. H., and R. He, 2003: Local and deep-ocean forcing contributions to anomalous water properties on the west Florida shelf. J. Geophys. Res., 108, 3184, doi:10.1029/ 2002JC001407

_ B. D. Black, and H. Yang, 1996: Seasonal modulation of the west Florida continental shelf circulation. Geophys. Res. Lett., 23, 2247-2250.

$\ldots,-\ldots$, and Z. Li, 2000: An upwelling case study on Florida's west coast. J. Geophys. Res., 105, 11 459-11 469.

, Z. Li, and F. E. Muller-Karger, 2001: West Florida shelf response to local wind forcing: April 1998. J. Geophys. Res., 106, 31 239-31 262.

_ R. He, Y. Liu, and J. Virmani, 2005: West Florida shelf circulation on synoptic, seasonal, and inter-annual time scales. Circulation in the Gulf of Mexico: Observations and Models, Geophys. Monogr., Vol. 161, Amer. Geophys. Union, 325-347.

Yang, H., and R. H. Weisberg, 1999: Response of the west Florida shelf circulation to climatological wind stress forcing. J. Geophys. Res., 104, 5301-5320. 